NASZA DERMATOLOGIA Online OUR DERMATOLOGY Online

Source of Support: Nil

Competing Interests: None

\section{FIXED DRUG ERUPTION OF THE EYELIDS. A DERMOSCOPIC EVALUATION}

\author{
Manuel Valdebran, Rogelio Isao Salinas, Nelly Ramirez, \\ Alba Rodriguez, Leyla Guzman, Silvia Marte, Max Suazo, \\ Esmirna Rosado
}

\author{
Instituto Dermatológico Dominicano y Cirugía de Piel "Dr. Huberto Bogaert Díaz" \\ C/Federico Velásquez, esq. Albert Thomas, Santo Domingo, República Dominicana
}

Corresponding author: Dr Manuel Valdebran

investigacion@valdebran.com

\begin{abstract}
Fixed drug eruption (FDE) usually appears as a solitary or a small number of pruritic, well circumscribed, erythematous macules that evolve into edematous plaques; these lesions typically resolve after discontinuation of the offending drug, leaving hyperpigmentation at the site of lesions. Fixed drug eruption has been mentioned previously as a disease model for elucidating the mechanism of how skin inflammation is caused by skin-resident $T$ cells, a multistep process that results in eventual tissue damage. In this article we discuss the utility of dermoscopy as an additional tool which gives significant information aiding us to infer these complex processes seen in FDE and thus to confirm the diagnosis.
\end{abstract}

Key words: dermoscopy; whale shark pattern; fixed drug eruption; histology eyelids. A dermoscopic evaluation. Our Dermatol Online. 2013; 4(3): 344-346.

\section{Introduction}

Fixed drug eruption (FDE) usually appears as a solitary or a small number of pruritic, well circumscribed, erythematous macules that evolve into edematous plaques; these lesions typically resolve after discontinuation of the offending drug, leaving hyperpigmentation at the site of lesions. They recur in exactly the same sites when rechallenged with each administration of the offending drug [1]. Although FDE may occur anywhere on the skin or mucous membrane, the most common locations are the lip, palms, soles, glans penis, and groin areas. Discrete lesions often appear in the same bilaterally symmetrical regions of the skin, particularly in the abdominal and the inner aspect of the arms and legs [2].

There have been many reports describing patients with typical FDE who had no significant history of drug intake preceding the eruptions. Some cases of recurrent exacerbations of FDE lesions without significant history of drug intake might be attributable to nonspecific exogenous factors. Nonmedical factors, such as food and ultraviolet irradiation, have been reported to precipitate exacerbations of FDE lesions [3-5].

FDE has been mentioned previously as a disease model for elucidating the mechanism of how skin inflammation is caused by skin-resident $\mathrm{T}$ cells, a complicated multistep process that results in eventual tissue damage [6]. This damage results when intraepidermal CD8 $+\mathrm{T}$ cells are activated to directly kill surrounding keratinocytes and release large amounts of cytokines such as IFN [gamma] into the local microenvironment. Cytokine or adhesion molecule-mediated nonspecific recruitment of CD4+, CD8+ T cells and neutrophils to a specific tissue site without recognition of their cognate antigen would serve to enhance tissue damage, thereby contributing to the late stages of development of FDE lesions [6,7].

\section{Case Report}

A 4-year-old female patient, Fitzpatrick skin type V, presented in our institution by his father with a 5-month history of a dermatosis affecting periocular area bilaterally, asymptomatic. Clinical examination revealed the presence of oval grayish-violaceous hyperpigmented patches around the eyelids bilateral (Fig. 1). A clinical diagnosis of fixed drug eruption was made. Dermoscopy revealed multiple grouped black, brown and in certain areas steel blue dots (Fig. 2). Histology reveals basal cell hydropic degeneration, Lymphocyte tagging along the dermoepidermic junction and perivascular, necrotic keratinocytes, in the upper and reticular dermis abundant melanophages and pigment incontinence (Fig. 3, 4). 


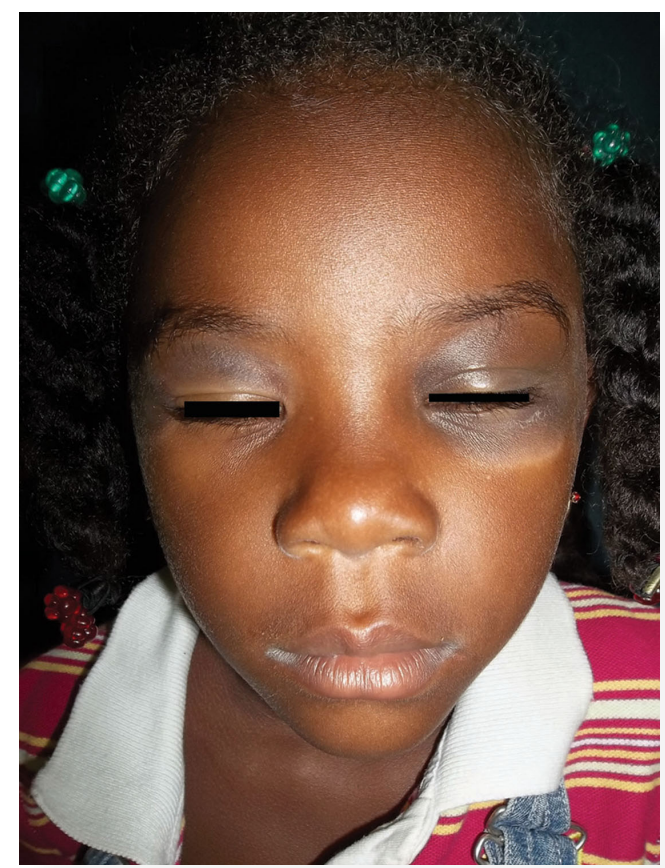

Figure 1. Periorbital greyish-violaceous hyperpigmented patches

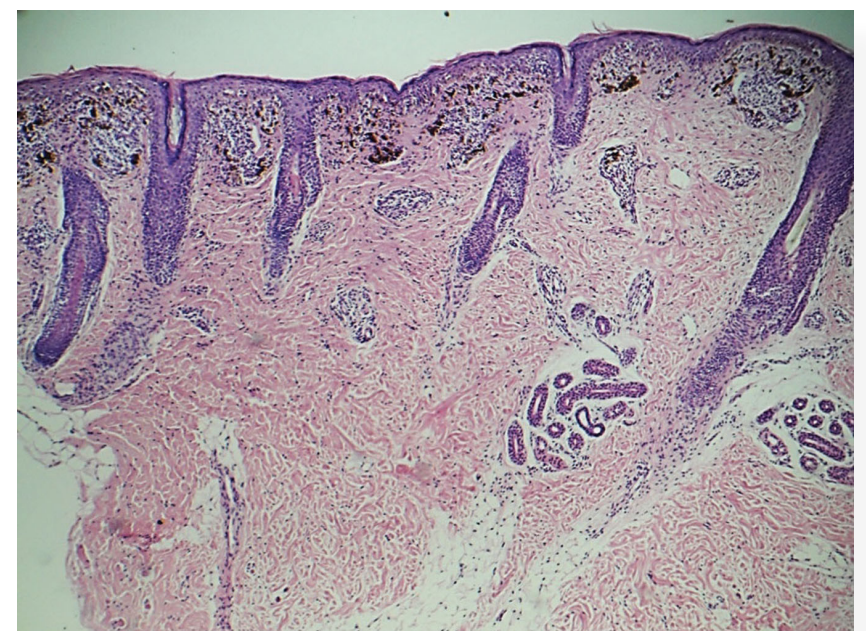

Figure 3. Flat epidermis with vacuolated cells. In superficialandmid-dermis, denseband-likeand perivascular inflammatory infiltrate. In follicular and perifollicular areas there is less melanic pigment.

\section{Discussion}

Dermoscopy is a noninvasive method that allows the in vivo evaluation of colors and microstructures of the epidermis, the dermoepidermal junction, and the papillary dermis not visible to the naked eye $[8,9]$.

Color variation of melanin depends on its location in the skin. In the stratum corneum and upper epidermis, melanin is jet black; in the basal layer and dermoepidermal junction, it is brown; in the papillary dermis it is blue-gray; and in the reticular dermis it is steel blue. Due to the Tyndall effect, in which shortwavelength visible light (blue) is dispersed and reflected more than long-wavelength light (red), the blue color of otherwise black melanin is explained by the depth of the pigment deep in the dermis (Fig. 5) [10].

These group of structures and colors describe patterns of presentation and are characterized by specifically correlated to histologic features.

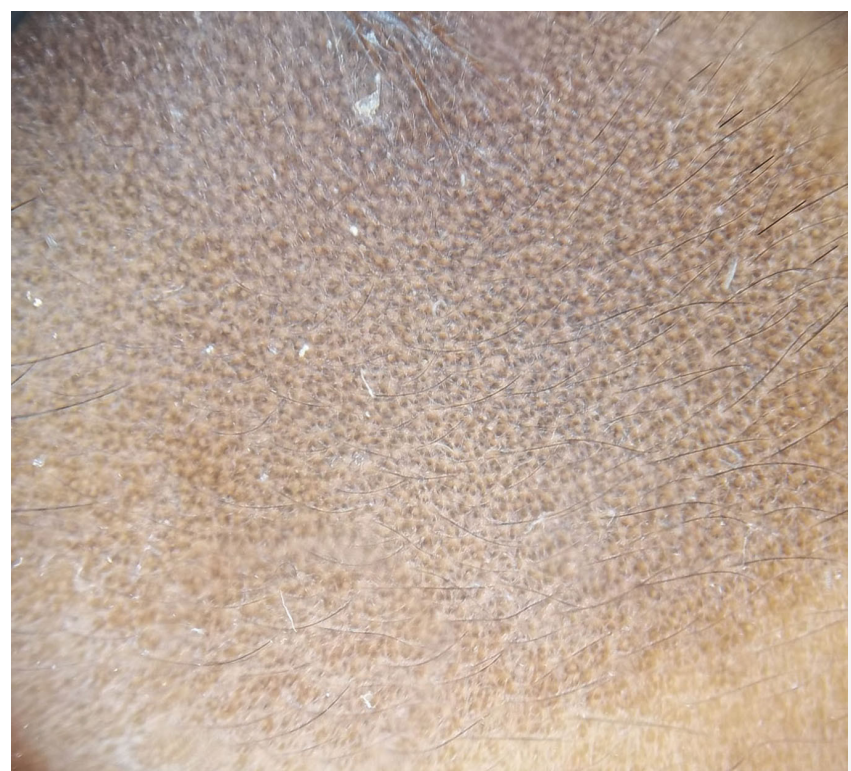

Figure 2. Grouped brown, gray and steel blue dots with perifollicular hypopigmentation in a 4-year-old girl

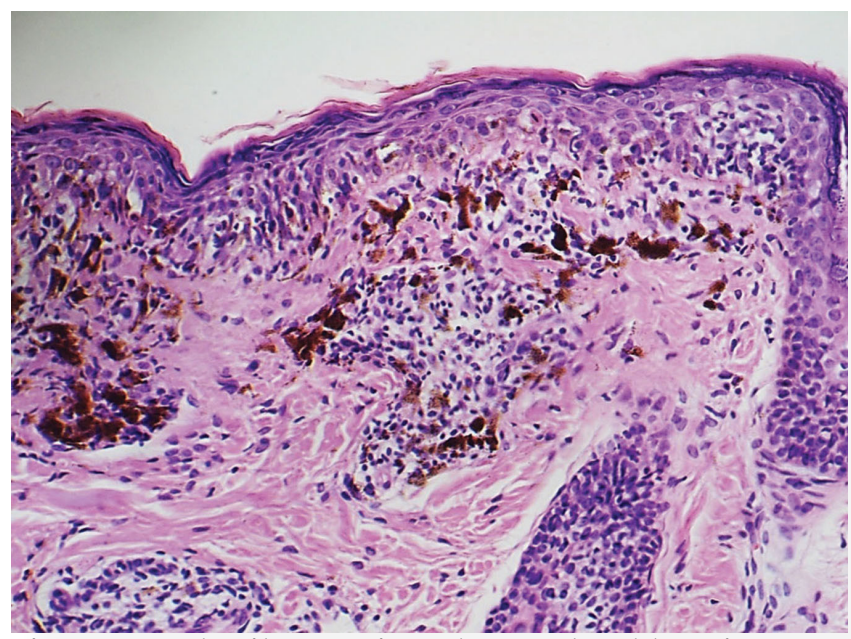

Figure 4. In detail, necrotic and vacuolated keratinocytes. In superficial and mid dermis, dense infiltrate of lymphocytes and abundant melanophages. H\&E 20X.

In the dermoscopy of the patient (Fig. 2) we observe black dots, light-to-dark brown dots, and steel blue. All this images grouped in a pattern that reminds the image of a whale shark (Fig. 6).

Dermoscopy in this case gives us an approximation of the histology, in which multiple dots colored form black to bluegray correspond to melanin deposition not only at different levels of the epidermis but also at different levels of the dermis, that information is crucial since we may assume there has been pigment incontinence and damage at the dermoepidermal junction produced by lymphocyte infiltrate.

We can conclude that proper dermoscopy evaluation can give the dermatologist an additional armamentum when aproaching to different dermatoses. Unconventional use of dermoscopy such in fixed drug eruption is valid and can give the dermatologist an information about what is happening underneath the skin. 


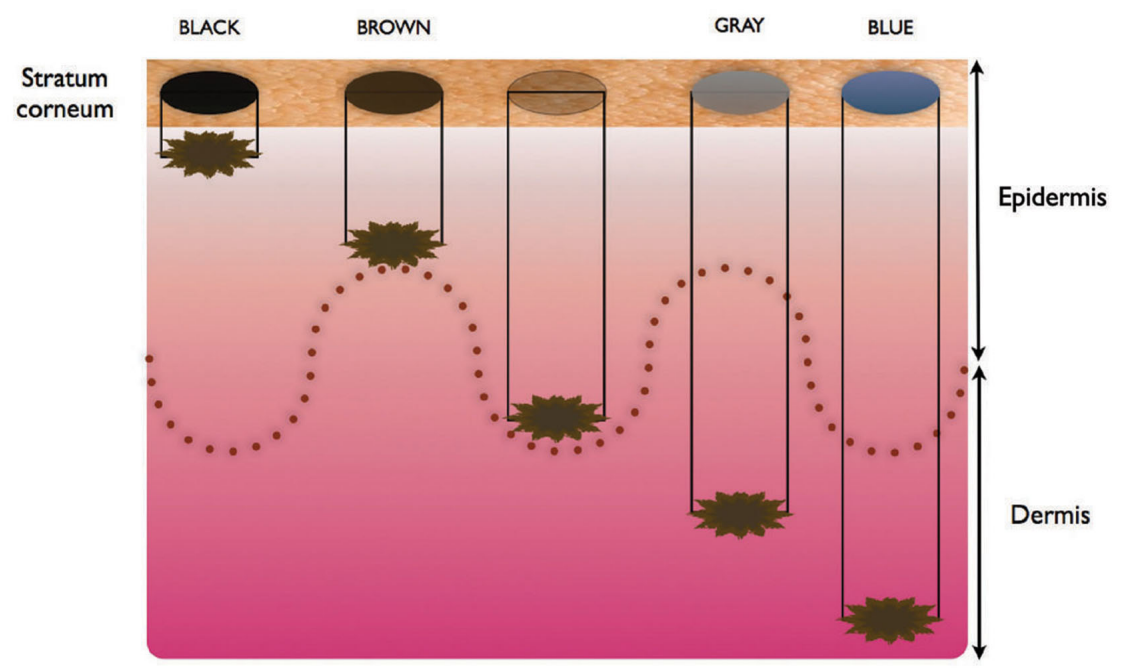

Figure 5. Skin color variations at different melanic pigmentation depths

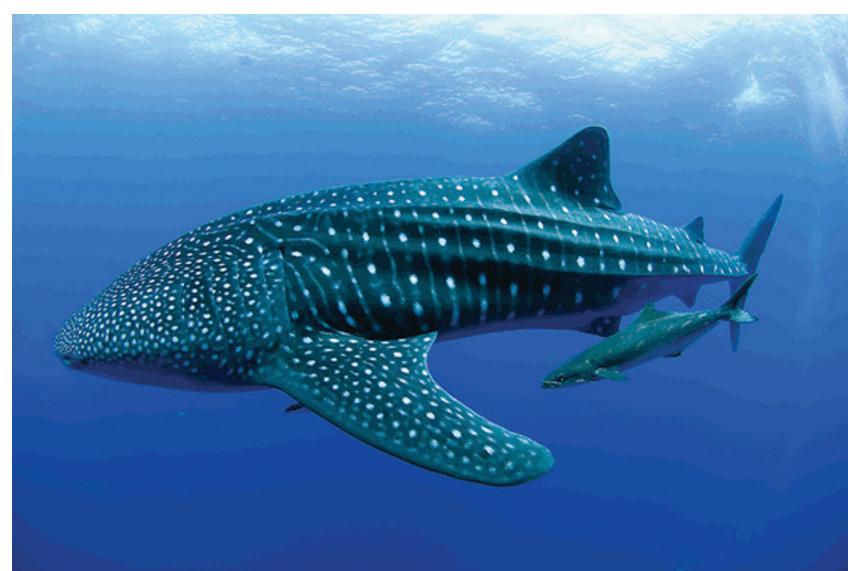

Figure 6. White dots in the surface of a whale shark

\section{REFERENCES}

1. Shiohara T, Mizukawa Y: Fixed drug eruption: a disease mediated by self-inflicted responses of intraepidermal T cells. Eur J Dermatol. 2007;17:201-8.
2. Korkij W, Soltani K: Fixed drug eruption. Arch Dermatol. 1984; 120:520-4.

3. Tsuruta D, Sowa J, Kobayashi H, Ishii M: Fixed food eruption caused by lactose identified after oral administration of four unrelated drugs. J Am Acad Dermatol. 2005;52:370-71.

4. Volz T, Berner D, Weigert C, Röcken M, Biedermann T: Fixed food eruption caused by asparagus. J Allergy Clin Immunol. 2005;116:1390-2.

5. del Río E, Guimaraens D, Aguilar A, Conde-Salazar L, Sánchez Yus E: Fixed exanthema induced by ultraviolet radiation. Dermatol. 1996;193:54-5.

6. Shiohara T: Fixed drug eruption: pathogenesis and diagnostic tests. Curr Opin Allergy Clin Immunol. 2009.;9:316-21.

7. Teraki Y, Moriya N, Shiohara T: Drug-induced expression of intercellular adhesion molecule-1 on lesional keratinocytes in fixed drug eruption. Am J Pathol. 1994;145:550-60.

8. Massone C, Di Stefani A, Soyer P: Dermoscopy for skin cancer detection. Curr Opin Oncol. 2005;17:147-53.

9. Soyer HP, Smolle J, Hödl S, Pachernegg H, Kerl H: Surface microscopy: a new approach to the diagnosis of cutaneous pigmented tumors. Am J Dermatopathol. 1989;11:1-10.

10. Weismann K. Lorentzen HF: Dermoscopic Color Perspective. Arch Dermatol. 2006:142:1250. 